OPEN ACCESS

Edited by:

David Meyre,

McMaster University, Canada

Reviewed by:

Yuvreet Kaur,

University of Toronto, Canada

Viswanathan Mohan,

Madras Diabetes Research

Foundation, India

${ }^{*}$ Correspondence:

Shafqat Ahmad

shafqat.ahmad@medsci.uu.se

Specialty section:

This article was submitted to

Genomic Endocrinology,

a section of the journal

Frontiers in Endocrinology

Received: 03 November 2018

Accepted: 20 March 2019

Published: 09 April 2019

Citation:

Ahmad S, Fatima SS, Rukh G and

Smith CE (2019) Gene Lifestyle Interactions With Relation to Obesity, Cardiometabolic, and Cardiovascular

Traits Among South Asians.

Front. Endocrinol. 10:221

doi: 10.3389/fendo.2019.00221

\section{Gene Lifestyle Interactions With Relation to Obesity, Cardiometabolic, and Cardiovascular Traits Among South Asians}

\author{
Shafqat Ahmad ${ }^{1,2,3 *}$, Syeda Sadia Fatima ${ }^{4}$, Gull Rukh ${ }^{5}$ and Caren E. Smith ${ }^{6}$ \\ ${ }^{1}$ Department of Medical Sciences, Molecular Epidemiology, Uppsala University, Uppsala, Sweden, ${ }^{2}$ Preventive Medicine \\ Division, Harvard Medical School, Brigham and Women's Hospital, Boston, MA, United States, ${ }^{3}$ Department of Nutrition, \\ Harvard T. H. Chan School of Public Health, Boston, MA, United States, ${ }^{4}$ Department of Biological and Biomedical Sciences, \\ Aga Khan University, Karachi, Pakistan, ${ }^{5}$ Department of Neuroscience, Functional Pharmacology, Uppsala University, \\ Uppsala, Sweden, ${ }^{6}$ Nutrition and Genomics Laboratory, Jean Mayer U. S. Department of Agriculture Human Nutrition \\ Research Center on Aging, Tufts University, Boston, MA, United States
}

The rapid rise of obesity, type 2 diabetes mellitus (T2DM) and cardiovascular disease (CVD) during the last few decades among South Asians has been largely attributed to a major shift in lifestyles including physical inactivity, unhealthy dietary patterns, and an overall pattern of sedentary lifestyle. Genetic predisposition to these cardiometabolic risk factors may have interacted with these obesogenic environments in determining the higher cardiometabolic disease prevalence. Based on the premise that gene-environment interactions cause obesity and cardiometabolic diseases, we systematically searched the literature and considered the knowledge gaps that future studies might fulfill. We identified only seven published studies that focused specifically on gene-environment interactions for cardiometabolic traits in South Asians, most of which were limited by relatively small sample and lack of replication. Some studies reported that the differences in metabolic response to higher physical activity and low caloric diet might be modified by genetic risk related to these cardiometabolic traits. Although studies on gene lifestyle interactions in cardiometabolic traits report significant interactions, future studies must focus on more precise assessment of lifestyle factors, investigation of a larger set of genetic variants and the application of powerful statistical methods to facilitate translatable approaches. Future studies should also be integrated with findings both using mechanistic studies through laboratory settings and randomized clinical trials for clinical outcomes.

Keywords: gene environment interaction, South Asians, obesity, cardiometabolic traits, cardiovasclar disease

\section{OVERVIEW}

About $20 \%$ of the world's population lives in the South Asian region comprised of Bangladesh, Bhutan, India, Nepal, Pakistan, and Sri Lanka (1). The burden of obesity (2), type 2 diabetes mellitus (T2DM) (3), cardiovascular disease (CVD) (4) is especially high in South Asian populations, partly because South Asians appear to be more genetically susceptible to CVD than, for example, white Europeans $(5,6)$. For example, the prevalence of CVD ranges from 5 to $10 \%$ in South Asians vs. 1.2 
in \% Caucasians (6); where age, male gender, smoking history, abnormal lipids, hypertension, and diabetes are considered as the major risk factors in both groups (7). CVD is projected to become the leading cause of mortality and morbidity among South Asians in the coming 20 years (8). Similarly, $8-15 \%$ of individuals in India (9), 26.0\% in Bangladesh (10), 13$14 \%$ in Sri Lanka (11), and $19 \%$ in Nepal (12) suffer from obesity; another alarming trigger for cardiometabolic and CVD pathogenesis. South Asians have several distinct features with respect to T2DM risk compared with other ethnic groups, including an earlier onset of disease and complications (13), occurrence at a lower BMI (2), insulin resistance (14), ectopic fat deposition (15), and younger age (16); therefore the World Health Organization (WHO) recently proposed an ethnicity based BMI cut-off to predict T2DM and CVD (17). South Asian countries are also shifting rapidly from traditional agricultural lifestyles to industrialized living, the health care infrastructure of many South Asian countries is under-developed and South Asian populations are aging rapidly $(18,19)$. Thus, there is a pressing need to understand the etiology of cardiometabolic and CVD at a global level, but in developing countries the urgency is even greater.

South Asians have experienced a considerable shift to a more automated lifestyle with fewer physically active behaviors and more energy dense foods, but there is a considerable variability in the extent to which obeso-genic environments increase the risk of cardiometabolic and CVD related disease. These differences in response have been reported in randomized clinical trials (20) as well as migration studies (21, 22), reflecting the impact of environment on cardiometabolic traits and CVD, while also supporting an important role of genetics. These literature findings strongly suggest that the development of cardiometabolic and CVD related disease is the consequence of interactions between genetic and environmental risk factors.

The Human Genome Project (HGP) was designed to map human genome with the identification of more than 20,500 human genes $(23,24)$. The products of this project provide details about the structure, function, physical location and organization of human genome, including differences in minor allele frequency and linkage equilibrium related to ancestry. After the successful sequencing of 3 billion nucleotides through HGP, the main focus was placed on the identification and cataloging of millions of SNPs. The knowledge from HGP made GWAS possible and contrasts with the conventional candidate gene approach in that it is performed in a fashion that does not rely on previous knowledge about genetic variants and traits. The GWAS approach is considered most unbiased approach for discovering genetic variants that affect susceptibility to disease.

GWAS studies focus on investigating the association between common genetic variants and traits within populations. Earlier GWAS studies led to the discovery of FTO rs9939609 genetic variant in association with obesity among Europeans (2527). After this early wave of GWAS studies, a major shift in GWAS studies took place that resulted in collaboration between geneticists to facilitate pooling of study specific data through meta-analysis. The increase in statistical power that accompanied these large studies ultimately led to the detection of small association signals. Regarding obesity traits, the formation of the 'Genetic Investigation of ANthropometric Traits (GIANT), a large international consortium, is the most prominent example. In one of the first efforts of the GIANT consortium, GWAS summary statistics of 16,876 participants from seven European ancestry studies were meta-analyzed and led not only to the confirmation of FTO rs9939609 variant but also identified MC4R rs17782313 genetic variant in association with BMI (28). In the recent wave of discovery by the efforts of GIANT consortium, GWAS has led to the identification of 97 BMI-associated and 49 BMI adjusted waist-hip ratio associated reproducible genetic variants $(29,30)$. In an effort to discover low frequency $(<5 \%$ minor allele frequency) variants, Turcot et al. used a sample of 718,734 individuals to identify 14 protein coding variants (31). Pulit et al. using a sample of 694,649 individuals identified 463 genetic variants that associate with BMI adjusted waist-hip ratio (32).

Similar collaborative efforts involving pooling of GWAS summary statistics data regarding T2DM and CVD-related traits led to the foundation of the MAGIC (Diabetes Genetics Replication and Meta-analysis) and the GLGC (Global Lipids Genetics Consortium), consortia, respectively. In the recent wave of discovery by the efforts of the MAGIC consortium, more than 65 genetic variants associated with glycemic traits have been identified $(33,34)$. Kooner et al. identified six T2DM associated genetic loci in a sample of 18,731 cases of T2DM and 39,856 disease free individuals from South Asia (35). Similarly, GWAS collaborative efforts of GLGC consortium led to publication of 157 robustly associated genetic variants in association with CVD related traits $(36,37)$. These genetic variants discovered though GWAS explain $<5 \%$ of genetic variation in obesity $(29,30),<15 \%$ in lipid traits $(36,37)$, and $<11 \%$ in T2DM related traits (34). Estimates for the heritability of obesity, T2DM and CVD mostly range from 40 to $70 \%$, showing that a large proportion of genetic risk still remained to be discovered. While the specific genetic mutations that lead to the high heritability estimates observed for obesity, cardiometabolic and CVD have been studied extensively in Europeans (29, 30, 33, 34, 36-39), very few GWAS studies have been reported in indigenous South Asian populations. An even smaller number of studies have used gene environment approaches to investigate the high prevalence of CVD and its risk factors in South Asians.

The study of gene environment interactions provides useful insight to investigators across several disciplines. Recognition that genes interact with the environment to influence anthropometric, cardiometabolic and CVD traits is highly relevant to public health research. For geneticists, it is also important to understand how lifestyle factors interact with genetic predisposition to affect gene expression, function, regulation, and other genetic features that lead to the development of a disease. In addition, studying geneenvironment interactions is important as it helps to optimize health interventions by targeting the individuals who respond well, can reduce unnecessary intervention side effects, and also can identify novel interventions that are specifically effective in a population subgroup of genetically similar people. 
The GWAS approach has been very successful in identifying the common genetic variants. Follow-up of genetic variants that were discovered through GWAS to investigate gene environment interactions is generally very feasible, as these genetic loci are usually genotyped in huge epidemiological samples which also contain extensive lifestyle and clinical information. However, even with large epidemiological samples, only a few genetic variants that were discovered through conventional GWAS approach have shown convincing evidence that lifestyle factors can modify the anthropometric (40) and cardiometabolic disease risk (41) in Europeans. Just to reiterate, the objective of the current literature review was not to compare different statistical methodological approaches for discovering potential genetic variants for studying gene environment interactions which has been discussed elsewhere (42).

\section{OBJECTIVE OF THIS REVIEW}

In this review we intend to discuss the published studies in South Asians regarding gene and lifestyle factors including physical activity, smoking, and dietary patterns interactions in the development of obesity, cardiometabolic and CVD disease related biomarkers of insulin resistance, glucose metabolism, lipids, blood pressure, and inflammation.

\section{Methodology}

A literature search was performed on studies related to obesity, cardiometabolic and CVD related diseases with respect to interaction of genes and lifestyles including physical activity, smoking, sleep disorders, and dietary intakes in PubMed and Google Scholar. We carried out a literature search using the term gene environment in South Asians, as has been described in the Supplementary Note. For the current study we only identified seven original published articles (not the published reviews) (as shown Table 1) that investigated gene environment interactions in obesity, T2DM and CVD related traits among South Asians. We also searched the published articles by the name of genetic epidemiologists working explicitly with cardiometabolic and cardiovascular related traits among South Asians.

\section{Gene Environment Interactions for Obesity Among South Asians}

The high prevalence of obesity is believed to be the result of genetic susceptibility and lifestyle factors and more than 200 interaction studies have been reported in Europeans (40). Among South Asians, Ahmad et al. (43) performed one of the first studies using data from 16,157 Pakistani adults of Pakistan Risk of Myocardial infarction (PROMIS) study, and studied the interactions between 95 BMI associated genetic variants with physical activity for the risk of obesity. The authors reported that out of $95 \mathrm{BMI}$-associated genetic variants discovered in Europeans, 73 were directionally associated with the risk of BMI in South Asians. However, these 95 BMIassociated variants explained less (1.54\%) of the phenotypic variance in BMI among South Asians compared to 2.7\% among Europeans. In the overall Pakistani sample each unit increase in the genetic risk score for BMI was associated with $0.04 \mathrm{~kg} / \mathrm{m}^{2}$ increase in BMI per allele; $P=4.5 \times 10^{-14}$ ). The authors also observed nominal significant interactions of GALNT10 rs7715256 $\left(P_{\text {interaction }}=0.048\right), C A D M 2$ rs13078960 $\left(P_{\text {interaction }}\right.$ $=0.037)$, and CLIP1 rs11057405 $\left(P_{\text {interaction }}=0.014\right)$ with physical activity, while HIP1 rs1167827 $\left(P_{\text {interaction }}=0.015\right)$, C6orf106 rs205262 ( $\left.P_{\text {interaction }}=0.032\right)$, PTBP2 $\operatorname{rs} 11165643$ $\left(P_{\text {interaction }}=0.045\right)$, and GRID1 rs7899106 $\left(P_{\text {interaction }}=0.043\right)$ genetic variants showed significant interactions with smoking on the risk of obesity. Although interactions with individual variants were observed, the authors did not observe any evidence of significant interactions between the BMI-specific genetic risk score with physical activity or smoking on the risk of obesity.

Recently, the Toronto Nutrigenomics and Health Study investigated the interactions between dietary macronutrients and variants in the FTO gene using a cross-sectional sample of 1,639 different ancestries sample including 174 South Asians individuals. The authors reported no association between FTO rs1558902 variant with the risk of adiposity in South Asians (46). The authors also observed that protein intake did not modify the genetic risk of the same FTO variant on adiposity, as had been reported in Europeans. The study sample is relatively small and might be underpowered to detect any reliable genetic association or gene diet interactions in South Asians. Moreover, this example illustrates the critical need for larger samples of South Asians for genetic studies.

Similarly, Reddon et al. (45) using the longitudinal, multiethnic cohort of EpiDREAM comprised of 17,423 subjects including 2,760 individuals of South Asian ancestry reported that vigorous physical activity ameliorated obesity in genetically susceptible subgroups. The authors reported significant interactions between physical activity and FTO rs1421085 genetic variant on the risk of BMI $\left(P_{\text {interaction }}=\right.$ 0.03). One of the caveats of the study was that it did not report ethnic-specific gene diet interactions despite having a multiethnic sample.

Several of the studies described above use the GWAS approach which has been very successful in identifying associations between common genetic variants and disease traits but less able to identify gene lifestyle interactions. The heterogeneity of variance (HeVa) approach extends the conventional GWAS approach by taking into account the trait variance across three different genotypes of a biallelic single nucleotide polymorphism (SNP), which reflects a different mode of genetic influence regarding interactions. $\mathrm{HeVa}$ approach tests whether interactions are present by testing a trait significantly differs across three genotypes of a SNP locus $(50,51)$. So, in that way HeVa is preferred over the GWAS approach in detecting the potential candidates for gene environment interactions, although it needs to be remembered that heterogeneity can be driven through gene-gene or other interacting factors, such as lifestyle. By using the $\mathrm{HeVa}$ approach in the sample of 14,131 individuals of PROMIS study from Pakistan, Ahmad et al. identified FLJ33534 rs140133294 variant in association with the variance of BMI and also the same variant interacted with smoking $\left(P_{\text {interaction }}=\right.$ 0.0005) (44). The HEVA approach has been considered as one of the powerful tools for discovering potential gene environment interactions. However, recently Shungin et al. reported that 
TABLE 1 | List of studies published regarding gene-environment interactions in obesity, cardiometabolic, and cardiovascular diseases among South Asian.

\begin{tabular}{|c|c|c|c|c|c|c|}
\hline Authors & Study type & Sample $(N=)$ & Study population & Interactor variable & Genetic variants & Outcome \\
\hline Ahmad et al. (43) & Case-control & 16,157 & South Asian & Physical activity & $\begin{array}{l}97 \mathrm{BMl} \text { associated } \\
\text { SNPs }\end{array}$ & $\mathrm{BMl}$ \\
\hline Ahmad et al. (44) & Case-control & 14,131 & South Asian & smoking & $\begin{array}{l}\text { GWAS, FLJ35541 } \\
\text { genetic variant }\end{array}$ & $\mathrm{BMl}$ \\
\hline Reddon et al. (45) & Cross-sectional & 2760 & $\begin{array}{l}\text { Multi-ethnic including } \\
\text { South Asians }\end{array}$ & Physical activity & FTO & Obesity \\
\hline Merrit et al. (46) & Cross-sectional & 174 & $\begin{array}{l}\text { Multi-ethnic including } \\
\text { South Asians }\end{array}$ & Dietary protein intake & FTO & Body weight \\
\hline Vimaleswaran et al. (47) & Cross-sectional & 1618 & South Asians & lifestyle factors & $\mathrm{FTO}$ & Metabolic traits \\
\hline Ayyappa et al. (48) & Case control & 1845 & South Asian & High fat diet & LPL (lipoprotein lipase) & HDL-C \\
\hline Bodhini et al. (49) & Cross-sectional & 1682 & South Asian & Dietary fat intake and PA & TCF7L2 and MC4R & HDL-C \\
\hline
\end{tabular}

efficiency of potential targets for gene environment interactions could be improved by focusing genetic variants with low $p$-values discovered through marginal GWAS effects in combination with the HEVA approach (52).

\section{Gene Environment Interactions in Type 2 Diabetes Among South Asians}

In addition to the growing number of studies investigating BMI in South Asians, other groups have focused on T2DM. Vimaleswaran et al. (47) using a sample of 734 T2DM prevalent cases and 884 disease free participants from the Chennai Urban Rural Epidemiology Study (CURES) reported a novel gene diet interaction between genetic variants and diet for obesity traits and diabetes in an Asian Indian population. The authors selected two FTO associated genetic variants (rs8050136 and rs11076023). The findings suggested that minor allele carriers of FTO rs8050136 who consumed high carbohydrate had higher risk of developing obesity traits (47). The authors also observed a significant interaction between FTO rs11076023 genetic variant and dietary fiber intake $\left(P_{\text {interaction }}=0.0008\right)$ where individuals carrying AA genotypes with higher fiber intake had $1.62 \mathrm{~cm}$ lower waist circumference than among those carrying the TT genotype. Further, the authors observed that physically inactive individuals carrying the A allele of rs8050136 FTO SNP had 1.89 times significantly increased risk of obesity compared to those with CC genotype $\left(P_{\text {interaction }}=4.0 \times 10^{-5}\right)$.

\section{Gene-Environment Interactions in CVD Related Traits Among South Asians}

Ayyappa et al. (48) analyzed the association of four (rs285, rs328, rs4922115, and rs1121923) lipoprotein lipase gene ( $L P L)$ associated variants with blood lipids. The authors investigated whether dietary fat intake can modify the genetic risk of abnormal lipids in a sample of 1,845 individuals comprised of 788 T2DM prevalent cases and 1,057 healthy participants from India. The authors observed significant interactions between $L P L$ rs1121923 genetic variant and dietary fat intake on HDL $\left(P_{\text {interaction }}=0.003\right)$, specifically that among consumers of a high fat diet, individuals carrying $\mathrm{T}$ allele of rs1121923 had higher HDL-C levels.
Bodhini et al. (49) used a cross-sectional study of 861 prevalent cases of T2DM and 821 normally glucose tolerant participants from the Chennai Urban Rural Epidemiology Study (CURES). The authors examined whether the association of MC4R rs17782313 and TCF7L2 (rs12255372 and rs7903146) gene variants and cardiometabolic traits could be modified by physical activity and dietary intake. Authors observed significant interactions between TCF7L2 rs12255372 and dietary fat intake on the outcome of HDL-C ( $\left.P_{\text {interaction }}=0.0001\right)$. Low total dietary fat intake positively modifies the HDL-C levels in this Asian Indian population, despite their carrying the risk genotype $(\mathrm{GT}+\mathrm{TT})$ of TCF7L2 rs12255372. In sensitivity analyses authors also observed significant interactions between poly unsaturated fatty acids and the TCF7L2 rs 12255372 variant on HDL-C $\left(P_{\text {interaction }}<0.0001\right)$. This finding is of public health significance given that among Asian Indians low fat intake improves HDL-C among those carrying higher genetic risk for low HDL-C, which puts them at markedly increased risk for CVD (49).

\section{CHALLENGES IN GENE-ENVIRONMENT INTERACTIONS}

Gene lifestyle interaction studies can be very effective in disentangling the biological pathways for predicting disease development. These studies can also address the problem of missing heritability in several ways. First, interaction studies may identify cardiometabolic-related genetic variants which exert their effects more visibly through interaction with different lifestyle exposures. Second, gene lifestyle interactions can also be used for identifying the environmental factors that affect persons with specific genotypes (53). However, it remains a major challenge to identify interactions in cardiometabolic and cardiovascular diseases due to considerable limitations including imprecise measurement of lifestyle factors, small sample size, and limited statistical power, meta-analytic combinations of many small sample studies with heterogeneous lifestyle assessment and lack of replication [as has been described elsewhere $(40,54)]$. Ideally, in order to reduce the probability of false positive findings, a sample comprising thousands of participants is required for gene environment interaction studies 
which unfortunately is not available for many studies. Recent efforts in the establishment of large population based prospective cohorts (e.g., UK Biobank Study [https://www.ukbiobank.ac. uk/], Million Veteran Program [https://www.research.va.gov/ mvp/], Estonian Genome Centre [https://www.geenivaramu.ee/ en/about-us/estonian-genome-centre] and Finnish Precision Medicine Initiatives have provided robust and repeated measurements of lifestyle exposures over time in European populations. The UK biobank sample, in particular, has already led to some of the robust examples of gene lifestyle interactions in cardiometabolic traits (55-58). However, in South Asian populations, it still remains a challenge to conduct gene lifestyle interaction studies as there are only a few studies with relatively large samples. However, there are many existing epidemiological cohorts which can potentially be genotyped for studying genelifestyle interactions in cardiometabolic traits among South Asians. Determination of cardiometabolic disease-specific epigenetic, transcriptomic, proteomics, and human microbiota changes and integration of that information with genetic and lifestyle factors will provide more comprehensive insights and will prove valuable in predicting the onset and progression of obesity, cardiometabolic, and cardiovascular diseases.

\section{CONCLUSIONS}

Evidence shows that complex traits including obesity, cardiometabolic and CVD result from interaction between multiple genetic and environmental factors. During the last decade, the GWAS has led to identification of a number of genetic variants that associate with obesity, cardiometabolic and CVD traits, however, these genetic variants only explain a small phenotypic variation in these traits. Identifying genetic variants that predispose to cardiometabolic traits in combination with specific lifestyle exposures might be important for understanding the disease etiology and subsequently providing

\section{REFERENCES}

1. Jayawardena R, Ranasinghe P, Byrne NM, Soares MJ, Katulanda P, Hills AP. Prevalence and trends of the diabetes epidemic in South Asia: a systematic review and meta-analysis. BMC Public Health. (2012) 12:380. doi: 10.1186/1471-2458-12-380

2. Haslam D, Sattar N, Lean M. ABC of obesity: obesity-time to wake up. BMJ Br Med J. (2006) 333:640. doi: 10.1136/bmj.333.7569.640

3. Anjana RM, Deepa M, Pradeepa R, Mahanta J, Narain K, Das HK, et al. Prevalence of diabetes and prediabetes in 15 states of India: results from the ICMR-INDIAB population-based cross-sectional study. Lancet Diabetes Endocrinol. (2017) 5:585-96. doi: 10.1016/S2213-8587(17)30174-2

4. McAloon CJ, Boylan LM, Hamborg T, Stallard N, Osman F, Lim PB, et al. The changing face of cardiovascular disease 2000-2012: an analysis of the world health organisation global health estimates data. Int J Cardiol. (2016) 224:256-64. doi: 10.1016/j.ijcard.2016.09.026

5. Yusuf S, Reddy S, Ounpuu S, Anand S. Global burden of cardiovascular diseases: Part II: variations in cardiovascular disease by specific ethnic groups and geographic regions and prevention strategies. Circulation. (2001) 104:2855-64. doi: 10.1161/hc4701.099488

6. Forouhi NG, Sattar N, Tillin T, McKeigue PM, Chaturvedi N. Do known risk factors explain the higher coronary heart disease mortality better prevention and treatment strategies. The identification of gene lifestyle interactions may also help in disentangling the pathways involved in these complex diseases and will be beneficial for future drug development and therapy. Currently, the study of gene lifestyle interactions in cardiometabolic traits among South Asians has been challenged by insufficient knowledge, small sample size, and lack of replication compared to other ancestries i.e., Caucasians. The next generation of studies incorporating large epidemiological cohort studies utilizing genetic information and better environment measurement technologies can improve our understanding of the complex causes of obesity, cardiometabolic, and CVD diseases.

It is also important to recognize that, similar to the international collaborative efforts in the European cohorts, South Asian studies have taken the initiative to form collaborations to fill the knowledge gaps in terms of interaction studies between genetic and lifestyle factors. As these efforts continue to progress, more personalized strategies can be implemented in decreasing the burden of these increasingly prevalent noncommunicable diseases.

\section{AUTHOR CONTRIBUTIONS}

SA: contributed to the conception and design of the research; SA, SF, GR, and CS: contributed to the acquisition, analysis, and interpretation of the data; SA: drafted the manuscript; All coauthors critically revised the manuscript, agree to be fully accountable for ensuring the integrity and accuracy of the work, and read and approved the final manuscript.

\section{FUNDING}

SA was supported through a fellowship and research support from Swedish Heart-Lung Foundation $(20150711,20170988)$ and Nutricia Research Foundation (2016-T1). in South Asian compared with European men? Prospective follow-up of the Southall and Brent studies, UK. Diabetologia. (2006) 49:2580-8. doi: 10.1007/s00125-006-0393-2

7. Joshi P, Islam S, Pais P, Reddy S, Dorairaj P, Kazmi K, et al. Risk factors for early myocardial infarction in South Asians compared with individuals in other countries. JAMA. (2007) 297:286-94. doi: 10.1001/jama.297.3.286

8. Mathers CD, Loncar D. Projections of global mortality and burden of disease from 2002 to 2030. PLoS Med. (2006) 3:e442. doi: 10.1371/journal.pmed.0030442

9. Wild S, Roglic G, Green A, Sicree R, King H. Global prevalence of diabetes: estimates for the year 2000 and projections for 2030. Diabetes Care. (2004) 27:1047-53. doi: 10.2337/diacare.27.5.1047

10. Siddiquee T, Bhowmik B, Da Vale Moreira NC, Mujumder A, Mahtab H, Khan AK, et al. Prevalence of obesity in a rural Asian Indian (Bangladeshi) population and its determinants. BMC Public Health. (2015) 15:860. doi: 10.1186/s12889-015-2193-4

11. Arambewela MH, Somasundaram NP, Jayasekara HBPR, Kumbukage MP, Jayasena PMS, Chandrasekara CMPH, et al. Prevalence of chronic complications, their risk factors, and the cardiovascular risk factors among patients with type 2 diabetes attending the diabetic clinic at a Tertiary Care Hospital in Sri Lanka. J Diabetes Res. (2018) 2018:4504287. doi: $10.1155 / 2018 / 4504287$ 
12. Gyawali B, Sharma R, Neupane D, Mishra SR, van Teijlingen E, Kallestrup P. Prevalence of type 2 diabetes in Nepal: a systematic review and meta-analysis from 2000 to 2014. Global Health Action. (2015) 8:29088. doi: 10.3402/gha.v8.29088

13. Tillin T, Hughes AD, Mayet J, Whincup P, Sattar N, Forouhi NG, et al. The relationship between metabolic risk factors and incident cardiovascular disease in Europeans, South Asians, and African Caribbeans: SABRE (Southall and Brent Revisited) - a prospective population-based study. J Am Coll Cardiol. (2013) 61:1777-86. doi: 10.1016/j.jacc.2012.12.046

14. Sattar N, Gill JM. Type 2 diabetes in migrant south Asians: mechanisms, mitigation, and management. Lancet Diabetes Endocrinol. (2015) 3:1004-16. doi: 10.1016/S2213-8587(15)00326-5

15. Misra A, Soares MJ, Mohan V, Anoop S, Abhishek V, Vaidya R, et al. Body fat, metabolic syndrome and hyperglycemia in South Asians. J Diabetes Complicat. (2018) 32:1068-75. doi: 10.1016/j.jdiacomp.2018.08.001

16. Gupta R, Misra A, Vikram NK, Kondal D, Gupta SS, Agrawal A, et al. Younger age of escalation of cardiovascular risk factors in Asian Indian subjects. BMC Cardiovasc Disord. (2009) 9:1471-2261. doi: 10.1186/1471-2261-9-28

17. Joseph L, Wasir JS, Misra A, Vikram NK, Goel K, Pandey RM, et al. Appropriate values of adiposity and lean body mass indices to detect cardiovascular risk factors in Asian Indians. Diabetes Technol Ther. (2011) 13:899-906. doi: 10.1089/dia.2011.0014

18. Misra A, Khurana L. The metabolic syndrome in South Asians: epidemiology, determinants, and prevention. Metab Syndr Relat Disord. (2009) 7:497-514. doi: $10.1089 /$ met.2009.0024

19. Tripathy JP, Thakur JS, Jeet G, Chawla S, Jain S, Prasad R. Urban rural differences in diet, physical activity and obesity in India: are we witnessing the great Indian equalisation? Results from a cross-sectional STEPS survey. BMC Public Health. (2016) 16:816. doi: 10.1186/s12889-016-3489-8

20. Knowler WC, Barrett-Connor E, Fowler SE, Hamman RF, Lachin JM, Walker EA, et al. Reduction in the incidence of type 2 diabetes with lifestyle intervention or metformin. N Engl J Med. (2002) 346:393-403. doi: 10.1056/NEJMoa012512

21. Antecol $\mathrm{H}$, Bedard $\mathrm{K}$. Unhealthy assimilation: why do immigrants converge to American health status levels? Demography. (2006) 43:337-60. doi: $10.1353 /$ dem.2006.0011

22. Ebrahim S, Kinra S, Bowen L, Andersen E, Ben-Shlomo Y, Lyngdoh $\mathrm{T}$, et al. The effect of rural-to-urban migration on obesity and diabetes in India: a cross-sectional study. PLoS Med. (2010) 7:e1000268. doi: 10.1371/journal.pmed.1000268

23. McPherson JD, Marra M, Hillier L, Waterston RH, Chinwalla A, Wallis J, et al. A physical map of the human genome. Nature. (2001) 409:934-41. doi: 10.1038/35057157

24. Lander ES, Linton LM, Birren B, Nusbaum C, Zody MC, Baldwin J, et al. Initial sequencing and analysis of the human genome. Nature. (2001) 409:860-921. doi: $10.1038 / 35057062$

25. Rosskopf D, Bornhorst A, Rimmbach C, Schwahn C, Kayser A, KrügerGenge, A, et al. Comment on "A common genetic variant is associated with adult and childhood obesity”. Science. (2007) 315:187; author reply 187. doi: $10.1126 /$ science. 1130571

26. Frayling TM, Timpson NJ, Weedon MN, Zeggini E, Freathy RM, Lindgren $\mathrm{CM}$, et al. A common variant in the FTO gene is associated with body mass index and predisposes to childhood and adult obesity. Science. (2007) 316:889-94. doi: 10.1126/science.1141634

27. Dina C, Meyre D, Gallina S, Durand E, Körner A, Jacobson P, et al. Variation in FTO contributes to childhood obesity and severe adult obesity. Nat Genet. (2007) 39:724-26. doi: 10.1038/ng2048

28. Loos RJ, Lindgren CM, Li S, Wheeler E, Zhao JH, Prokopenko I, et al. Common variants near MC4R are associated with fat mass, weight and risk of obesity. Nat Genet. (2008) 40:768-75. doi: 10.1038/ng.140

29. Shungin D, Winkler TW, Croteau-Chonka DC, Ferreira T, Locke AE, Mägi R, et al. New genetic loci link adipose and insulin biology to body fat distribution. Nature. (2015) 518:187-96. doi: 10.1038/nature14132

30. Locke AE, Kahali B, Berndt SI, Justice AE, Pers TH, Day FR, et al. Genetic studies of body mass index yield new insights for obesity biology. Nature. (2015) 518:197-206. doi: 10.1038/nature14177

31. Turcot V, Lu Y, Highland HM, Schurmann C, Justice AE, Fine RS, et al. Protein-altering variants associated with body mass index implicate pathways that control energy intake and expenditure in obesity. Nat Genet. (2018) 50:26-41. doi: 10.1038/s41588-017-0011-x

32. Pulit SL, Stoneman C, Morris AP, Wood AR, Glastonbury CA, Tyrrell J, et al. Meta-analysis of genome-wide association studies for body fat distribution in 694649 individuals of European ancestry. Hum Mol Genet. (2019) 28:166-74. doi: 10.1093/hmg/ddy327

33. Scott RA, Lagou V, Welch RP, Wheeler E, Montasser ME, Luan J, et al. Largescale association analyses identify new loci influencing glycemic traits and provide insight into the underlying biological pathways. Nat Genet. (2012) 44:991-1005. doi: 10.1038/ng.2385

34. Morris AP, Voight BF, Teslovich TM, Ferreira T, Segrè AV, Steinthorsdottir $\mathrm{V}$, et al. Large-scale association analysis provides insights into the genetic architecture and pathophysiology of type 2 diabetes. Nat Genet. (2012) 44:98190. doi: 10.1038/ng.2383

35. Kooner JS, Saleheen D, Sim X, Sehmi J, Zhang W, Frossard P, et al. Genomewide association study in individuals of South Asian ancestry identifies six new type 2 diabetes susceptibility loci. Nat Genet. (2011) 43:984-9. doi: $10.1038 /$ ng.921

36. Teslovich TM, Musunuru K, Smith AV, Edmondson AC, Stylianou IM, Koseki $\mathrm{M}$, et al. Biological, clinical and population relevance of 95 loci for blood lipids. Nature. (2010) 466:707-13. doi: 10.1038/nature09270

37. Willer CJ, Schmidt EM, Sengupta S, Peloso GM, Gustafsson S, Kanoni S, et al. Discovery and refinement of loci associated with lipid levels. Nat Genet. (2013) 45:1274-83. doi: 10.1038/ng.2797

38. Speliotes EK, Willer CJ, Berndt SI, Monda KL, Thorleifsson G, Jackson AU, et al. Association analyses of 249,796 individuals reveal 18 new loci associated with body mass index. Nat Genet. (2010) 42:937-48. doi: 10.1038/ng.686

39. Willer CJ, Speliotes EK, Loos RJ, Li S, Lindgren CM, Heid IM, et al. Six new loci associated with body mass index highlight a neuronal influence on body weight regulation. Nat Genet. (2009) 41:25-34. doi: 10.1038/ng.287

40. Ahmad S, Varga TV, Franks PW. Gene $\mathrm{x}$ environment interactions in obesity: the state of the evidence. Hum Hered. (2013) 75:106-15. doi: 10.1159/000351070

41. Cornelis MC, Hu FB. Gene-environment interactions in the development of type 2 diabetes: recent progress and continuing challenges. Annu Rev Nutr. (2012) 32:245-59. doi: 10.1146/annurev-nutr-071811-150648

42. Franks PW, Paré G. Putting the genome in context: gene-environment interactions in type 2 diabetes. Curr Diabetes Rep. (2016) 16:57. doi: 10.1007/s11892-016-0758-y

43. Ahmad S, Zhao W, Renström F, Rasheed A, Samuel M, Zaidi M, et al Physical activity, smoking, and genetic predisposition to obesity in people from Pakistan: the PROMIS study. BMC Med Genet. (2015) 16:114. doi: 10.1186/s12881-015-0259-x

44. Ahmad S, Zhao W, Renström F, Rasheed A, Zaidi M, Samuel M, et al. A novel interaction between the FLJ33534 locus and smoking in obesity: a genome-wide study of 14131 Pakistani adults. Int J Obes. (2016) 40:186-90. doi: $10.1038 /$ ijo.2015.152

45. Reddon H, Gerstein HC, Engert JC, Mohan V, Bosch J, Desai D, et al. Physical activity and genetic predisposition to obesity in a multiethnic longitudinal study. Sci Rep. (2016) 6(18672). doi: 10.1038/srep18672

46. Merritt DC, Jamnik J, El-Sohemy A. FTO genotype, dietary protein intake, and body weight in a multiethnic population of young adults: a cross-sectional study. Genes Nutr. (2018) 13:4. doi: 10.1186/s12263-018-0593-7

47. Vimaleswaran KS, Bodhini D, Lakshmipriya N, Ramya K, Anjana RM, Sudha $\mathrm{V}$, et al. Interaction between FTO gene variants and lifestyle factors on metabolic traits in an Asian Indian population. Nutr Metab. (2016) 13:39. doi: 10.1186/s12986-016-0098-6

48. Ayyappa KA, Shatwan I, Bodhini D, Bramwell LR, Ramya K, Sudha V, et al. High fat diet modifies the association of lipoprotein lipase gene polymorphism with high density lipoprotein cholesterol in an Asian Indian population. Nutr Metab. (2017) 14:8. doi: 10.1186/s12986-016-0155-1

49. Bodhini D, Gaal S, Shatwan I, Ramya K, Ellahi B, Surendran S, et al. Interaction between TCF7L2 polymorphism and dietary fat intake on high density lipoprotein cholesterol. PLOS ONE. (2017) 12:e0188382. doi: 10.1371/journal.pone.0188382

50. Yang J, Loos RJ, Powell JE, Medland SE, Speliotes EK, Chasman DI, et al. FTO genotype is associated with phenotypic variability of body mass index. Nature. (2012) 490:267-72. doi: 10.1038/nature11401 
51. Paré G, Cook NR, Ridker PM, Chasman DI. On the use of variance per genotype as a tool to identify quantitative trait interaction effects: a report from the Women's Genome Health Study. PLoS Genet. (2010) 6:e1000981. doi: 10.1371/journal.pgen.1000981

52. Shungin D, Deng WQ, Varga TV, Luan J, Mihailov E, Metspalu A, et al. Ranking and characterization of established BMI and lipid associated loci as candidates for gene-environment interactions. PLoS Genet. (2017) 13:e1006812. doi: 10.1371/journal.pgen.1006812

53. Thomas D. Gene-environment-wide association studies: emerging approaches. Nat Rev Genet. (2010) 11:259-72. doi: 10.1038/nrg2764

54. Ahmad S, Rukh G, Varga TV, Ali A, Kurbasic A, Shungin D, et al. Gene $\mathrm{x}$ physical activity interactions in obesity: combined analysis of 111,421 individuals of European ancestry. PLoS Genet. (2013) 9:25. doi: 10.1371/journal.pgen.1003607

55. Frayling TM, Beaumont RN, Jones SE, Yaghootkar H, Tuke MA, Ruth KS, et al. A common allele in FGF21 associated with sugar intake is associated with body shape, lower total body-fat percentage, and higher blood pressure. Cell Rep. (2018) 23:327-36. doi: 10.1016/j.celrep.2018.03.070

56. Tyrrell J, Wood AR, Ames RM, Yaghootkar H, Beaumont RN, Jones SE, et al. Gene-obesogenic environment interactions in the UK Biobank study. Int J Epidemiol. (2017) 46:559-75. doi: 10.1093/ije/dyw337
57. Rask-Andersen M, Karlsson T, Ek WE, Johansson Å. Gene-environment interaction study for BMI reveals interactions between genetic factors and physical activity, alcohol consumption and socioeconomic status. PLoS Genet. (2017) 13:e1006977. doi: 10.1371/journal.pgen. 1006977

58. Young AI, Wauthier F, Donnelly P. Multiple novel gene-byenvironment interactions modify the effect of FTO variants on body mass index. Nat Commun. (2016) 7:12724. doi: 10.1038/ncomms 12724

Conflict of Interest Statement: The authors declare that the research was conducted in the absence of any commercial or financial relationships that could be construed as a potential conflict of interest.

Copyright (c) 2019 Ahmad, Fatima, Rukh and Smith. This is an open-access article distributed under the terms of the Creative Commons Attribution License (CC BY). The use, distribution or reproduction in other forums is permitted, provided the original author(s) and the copyright owner(s) are credited and that the original publication in this journal is cited, in accordance with accepted academic practice. No use, distribution or reproduction is permitted which does not comply with these terms. 